OPEN ACCESS

Edited by:

Penglei Chen,

Institute of Chemistry (CAS), China

Reviewed by:

Yingping Zou,

Central South University, China

Zuo-Quan Jiang,

Soochow University, China

LuKun,

National Center for Nanoscience and

Technology (CAS), China

*Correspondence:

Xinjun Xu

xuxj@bnu.edu.cn

Zhishan Bo

zsbo@bnu.edu.cn

tThese authors have contributed equally to this work

Specialty section: This article was submitted to

Supramolecular Chemistry, a section of the journal

Frontiers in Chemistry

Received: 27 February 2019 Accepted: 24 April 2019 Published: 15 May 2019

Citation:

Zhang C, Liu Y, Tu J, Ming S, Xu X and Bo Z (2019) Fluoro-Modulated

Molecular Geometry in

Diketopyrrolopyrrole-Based Low-Bandgap Copolymers for Tuning the Photovoltaic Performance.

Front. Chem. 7:333

doi: 10.3389/fchem.2019.00333

\section{Fluoro-Modulated Molecular} Geometry in DiketopyrrolopyrroleBased Low-Bandgap Copolymers for Tuning the Photovoltaic Performance

\author{
Cai'e Zhang ${ }^{\dagger}$, Yahui Liu ${ }^{\dagger}$, Jia Tu, Shouli Ming, Xinjun Xu* and Zhishan Bo* \\ Beijing Key Laboratory of Energy Conversion and Storage Materials, College of Chemistry, Beijing Normal University, Beijing,
} China

Fluorination of conjugated polymers is an effective strategy to tune the energy levels for obtaining high power conversion efficiency (PCE) in organic solar cells. In this work, we have developed fluoro-modulated molecular geometries in diketopyrrolopyrrole based low-bandgap copolymers. In these polymers, planar conformation can be locked by intramolecular non-covalent interaction (intramolecular supramolecular interaction) between the sulfur atoms and the introduced $F$ atoms (F...S interaction). By varying the fluorinated moieties, such a planarity can be disturbed and the molecular geometry is tuned. As a result, the polymer' properties can be modulated, including the ultraviolet-visible absorption spectrum to become broaden, charge mobility to be enhanced, open-circuit voltage $\left(V_{\text {oc }}\right)$ and short-circuited current $\left(J_{\mathrm{Sc}}\right)$ to be elevated, and thus photovoltaic performance to be improved. The photovoltaic device based on PCFB, one of the fluorinated terpolymers, exhibited a high PCE near $8.5 \%$ with simultaneously enhanced $V_{\text {oc }}$ and $J_{\text {SC }}$ relative to the non-fluorinated one (PCB).

Keywords: diketopyrrolopyrrole, fluorination, supramolecular interaction, polymer solar cell, photovoltaic performance

\section{INTRODUCTION}

Low-band gap (LBG) polymers have attracted lots of research attention due to their possibility to extend the absorption of solar spectrum from ultraviolet-visible (UV-vis) to near-infrared (NIR) region to make a good utilization of solar energy when used in organic solar cells (OSCs). They have the merits of enhancing the light absorption, realizing high-efficiency tandem solar cells with a wide bandgap polymer (Dou et al., 2012; You et al., 2013), and achieving semitransparent photovoltaic devices that strongly absorb light in the NIR region while allowing most of the visible light to get through (Dou et al., 2013). Among these LBG polymers, conjugated polymers employing diketopyrrolopyrrole (DPP) unit were frequently reported in the areas of organic field-effect transistors (OFETs) and OSCs in recent years (Hendriks et al., 2014a; Li et al., 2014b, 2018; Li C. et al., 2016; Yu et al., 2016). The DPP moiety usually has strong intermolecular interactions in the solid state including hydrogen bonding and $\pi-\pi$ interactions and its polar nature enhances the tendency of DPP-based polymers to crystallize (Sonar et al., 2010). As a result, DPP-based conjugated polymers often exhibit an advantageously tunable and broad optical absorption, high 


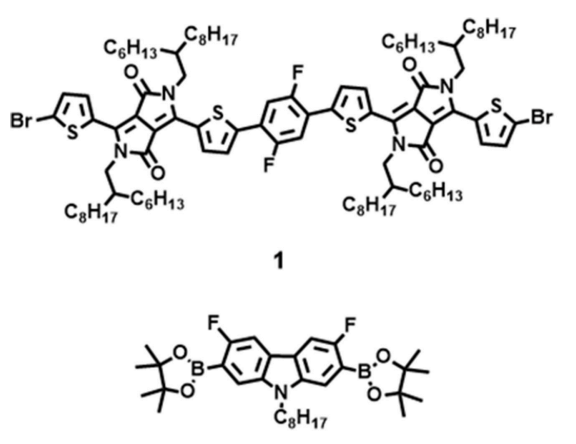

3

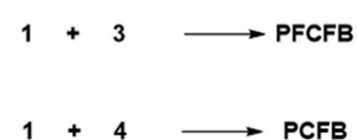

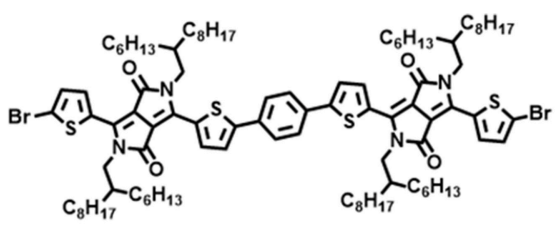

2

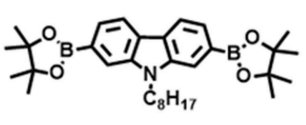

4

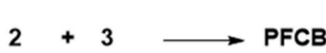

2

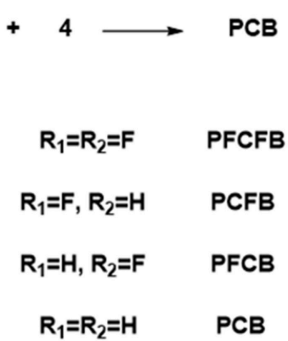

SCHEME 1 | Molecular structures and synthetic methods of the polymers.

charge carrier mobilities, and good nanoscale morphologies (Nielsen et al., 2013; Li et al., 2015; Wang et al., 2016), which can result in high photocurrents and good fill factors (FF) in OSCs. For instance, the optical absorption of the DPP based polymers can extend much farther into the NIR region (Hendriks et al., 2014b; Li et al., 2015), which provides wide photo-response in a long wavelength range to give a high short-circuit current $\left(J_{\mathrm{sc}}\right)$ in OSCs and can be applied in NIR organic photodetectors (Ashraf et al., 2015).

However, there are also some drawbacks in DPP based OSCs. Their open circuit voltage $\left(V_{\text {oc }}\right)$ was usually $<0.7 \mathrm{~V}$ due to their shallow highest occupied molecular orbital (HOMO) energy levels. Therefore, there are only several reports showed a power conversion efficiency (PCE) over $8 \%$ in single-junction OSCs based on DPP polymers (Hendriks et al., 2013; Choi et al., 2015; Zheng et al., 2016). There are several ways to adjust the energy level of polymers. One approach is to introduce electron-withdrawing groups in the backbone of the polymers. For example, poly (2,5-bis(2-decyltetradecyl )-pyrrolo[3,4-c]pyrrole-1,4(2H,5H)-dione-3,6-diyl-alt- $3^{\prime \prime}, 4^{\prime}$

-difluoro-2, $2^{\prime}: 5^{\prime}, 2^{\prime \prime}: 5^{\prime \prime}, 2^{\prime \prime \prime}$-quaterthiophene-5, $5^{\prime \prime \prime}$-diyl (PDPP4T$2 \mathrm{~F}$ ) was successfully designed by introducing two fluorine atoms to the 2,2'-bithiophene monomer which gave deeper energy level and higher $V_{\mathrm{oc}}$ (Zheng et al., 2016). Introducing $\mathrm{F}$ atom is also important in tailoring the chemical and physical properties of the resulting polymers (Albrecht et al., 2012; Li et al., 2014a). The non-covalent interaction of $\mathrm{F}$ atom not only exists in copolymers, but also can be observed in non-fullerene small molecule acceptors (Zhao et al., 2017; Liu et al., 2018). Because fluorine is the most electronegative element in the periodic table, the $\mathrm{F}$ atom is a powerful functional group for donor/acceptor materials. It has a quite strong electron-withdrawing nature, so the introduction of fluorine into the polymer/acceptor backbone can lower the HOMO and the lowest unoccupied molecular orbital (LUMO) energy level, resulting in the increase of $V_{\text {oc }}$. It is also believed that the fluorine atom offers non-covalent attractive interactions in a molecule (i.e., intramolecular supramolecular interaction) between the hydrogen or sulfur atoms, which may contribute to enhancing the coplanarity of the polymer backbone which would be favorable for the self-assembly and the crystallinity of the polymer (Li et al., 2014a; Kawashima et al., 2016; Zhang Q. et al., 2017). Another way to adjust the energy levels of polymers is to fabricate copolymers with different units. Recently, terpolymers which comprise three various components in the backbone have emerged as a new design strategy for donor polymers (Qin et al., 2014; Duan et al., 2016; Wang X. et al., 2017; Wang Y. et al., 2017; Huo et al., 2018). Among these copolymers, regioregular ones provide natural advantages, such as well-defined molecular structure, highly reproducibility and better molecular packing (Qin et al., 2014; Kim et al., 2015; Lee et al., 2015). Based on the above thinking, DPP based regioregular terpolymer with difluorobenzene and difluorocarbazole units was successfully fabricated and applied as donor material for OSCs in our previous work with a high $V_{\text {oc }}$ of $0.86 \mathrm{~V}$ and PCE over $8 \%$ (Liu et al., 2016). 
Despite such advantages of $\mathrm{F}$ substitutions to the properties of donor polymers, some reports demonstrated that excessive $\mathrm{F}$ atoms would reduce the photovoltaic performance due to the significantly aggravated aggregation of polymer chains and enhanced trap-assisted charge recombinations (Jo et al., 2015; Kawashima et al., 2016; Lee et al., 2016). It should be noted that such results were all obtained based on donor-acceptor (D-A) alternating binary copolymers. However, investigations of the effect of fluorine substitutions on both LBG terpolymers and DPP based copolymers are all currently absent. How the $F$ atoms will affect the properties of such copolymers and their photovoltaic performance? With these questions in mind, here we expect to investigate the photovoltaic performance of DPPbased terpolymers by introducing fluorine atoms into different moieties of the polymer backbone and adjusting the number of fluorine atoms so as to modulate their properties. In this work, four polymers (PFCFB, PCFB, PFCB, and PCB) were designed by altering $\mathrm{F}$ atoms in the monomers. They were synthesized with Suzuki coupling and exhibited similar molecular weight. Their HOMO energy levels were significantly reduced with the introduction of $\mathrm{F}$ atoms which gave higher $V_{\mathrm{oc}}$ in the photovoltaic device. F atoms was able to flatten the adjacent aromatic units because of the F. .S and F. . H interactions. The F. .S and F. . H interactions are ultimately electrostatic interaction. In the previous literature (Fei et al., 2015), according to density functional theory (DFT) calculations, positively charged sulfur atom $(+0.308)$ and negatively charged fluorine atom $(-0.281)$ tend to form strong electrostatic interaction. However, hydrogen atom $(+0.148)$ is less positively charged than sulfur atom, so F...S rather than F...H intramolecular interaction is preferred in our polymer backbone. Besides, Yan et al obtained single crystal structure of the model compounds (Li Z et al., 2016). The observations of F. . S interactions dominate the conformation or geometry. Therefore, we think the backbone of our polymer tend to form F. . S intramolecular interaction. In addition, the FF was decreased with the diminution of $\mathrm{F}$ atom. The photovoltaic device based on PFCFB exhibited the highest PCE of $8.48 \%$ with a highest $V_{\text {oc }}$ of $0.86 \mathrm{~V}$ and the device based on PCFB displayed a similar PCE of $8.46 \%$ with the highest $J_{\mathrm{sc}}$ of $17.20 \mathrm{~mA} \mathrm{~cm} \mathrm{~cm}^{-2}$, which are all improved relative to that of devices based on the non-fluorinated polymer (PCB).

\section{RESULTS AND DISCUSSION}

The synthetic route of polymers PFCFB, PCFB, PFCB, and PCB was shown in Scheme 1 (see Table S1). The original monomers $\mathbf{1}, \mathbf{2}, \mathbf{3}$, and $\mathbf{4}$ were synthesized as reported (Du et al., 2013; Park et al., 2013; Liu et al., 2016). These polymers can be acquired by Suzuki coupling using $\mathrm{Pd}\left(\mathrm{PPh}_{3}\right)_{4}$ as the catalyst. The molecular weights of these polymers via gel permeation chromatography (GPC) measurements are listed in Table 1. It is worth noting that high number-average molecular weight over $250 \mathrm{~kg} / \mathrm{mol}$ can be acquired with facile Suzuki polymerization for these polymers.

UV-vis spectra of polymers were investigated in thin films (Figure 1A). These polymers show similar absorption in visible light region with two absorption bands. The one located at shorter wavelength can be attributed to the localized $\pi-\pi^{*}$ transition and the strong peaks located at longer wavelength originate from the intramolecular charge transfer (ICT) (Tanaka et al., 2013). The absorption edges of these polymers are not the same. Optical bandgaps $\left(E_{\mathrm{g}}\right)$ calculated from the absorption edges of these polymers are listed in Table 1. It shows that fluorination of the polymer backbone reduces the optical bandgap. In addition, the dominant absorption peak of PCFB $(\sim 740 \mathrm{~nm})$ is slightly red-shifted compared with that of other polymers. This result can be explained by the shorter lamellar distance existing in PCFB film as validated from Xray diffraction (XRD) data (vide infra, see Figure S1, Table S2), which indicates that the polymer chains were packed more tightly (Wang Y. et al., 2017). The electrochemical properties were also investigated by cyclic voltammetry $(\mathrm{CV})$. Based on the $\mathrm{CV}$ results, energy levels of these polymers can be calculated according to the equations: $E_{\mathrm{HOMO}}=-e\left[E_{\mathrm{Ox}, \text { onset }}-E_{(\mathrm{Fc} / \mathrm{Fc}+)}+\right.$ 4.8] (Li G. et al., 2016; Zhang C. E. et al., 2017), and $E_{\mathrm{LUMO}}$ $=E_{\mathrm{HOMO}}+E_{\mathrm{g}, \mathrm{opt}}$, where $E_{\mathrm{g}, \mathrm{opt}}$ is the optical bandgap of the polymer. The detailed information is shown in Figure 1B, Table 1. As expected, the HOMO energy level was tunable and lowered in an observable scale with the introduction of $\mathrm{F}$ atoms, which is consistent with literature (Liu et al., 2018). Inevitably, the $V_{\text {oc }}$ of corresponding devices is affected, which will be discussed further below. The thermostability was investigated with thermogravimetric analysis (TGA) shown in Figure S2 which indicates good thermal stability with a decomposition temperature over $350^{\circ} \mathrm{C}$ with a weight loss of $5 \%$ under nitrogen atmosphere. The packing behaviors of PFCFB, PCFB, PFCB, and PCB in films was surveyed by XRD measurements. All of these polymers exhibit two diffraction peaks. As displayed in Figure S1, Table S2, one set of the diffraction peaks in PFCFB, PCFB, PFCB, and PCB films are located at $2 \theta$ of $4.76^{\circ}$, $4.84^{\circ}, 4.75^{\circ}$, and $4.79^{\circ}$, corresponding to lamellar distances of $18.58,18.26,18.61$, and $18.44 \AA$, respectively. Diffraction peaks arising from the $\pi-\pi$ stacking of backbones appeared at $2 \theta$ of $24.03^{\circ}, 23.85^{\circ}, 23.92^{\circ}$, and $23.63^{\circ}$, corresponding to distances of $3.70,3.73,3.72$, and $3.77 \AA$ for PFCFB, PCFB, PFCB and

TABLE 1 | The physical, optical, and electrical properties of polymers.

\begin{tabular}{|c|c|c|c|c|c|c|c|}
\hline Polymer & $M_{\mathrm{n}}(\mathrm{kg} / \mathrm{mol})$ & $M_{\mathrm{w}}(\mathrm{kg} / \mathrm{mol})$ & PDI & $\lambda_{\max }(\mathrm{nm})$ in film & $E_{\mathrm{g}, \mathrm{opt}}(\mathrm{eV})$ & HOMO (eV) & LUMO $(\mathrm{eV})$ \\
\hline PFCFB & 264 & 728 & 2.8 & $403,677,738$ & 1.57 & -5.31 & -3.74 \\
\hline PCFB & 284 & 1,006 & 3.5 & $393,678,742$ & 1.55 & -5.29 & -3.74 \\
\hline PCB & 278 & 923 & 3.3 & $387,667,728$ & 1.60 & -5.25 & -3.65 \\
\hline
\end{tabular}



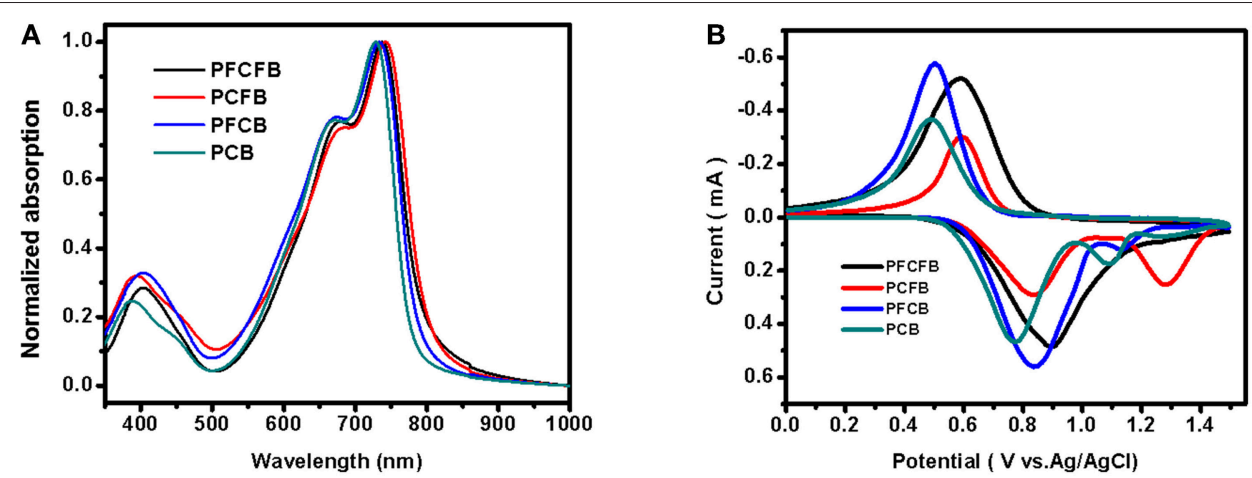

FIGURE 1 | UV-vis spectra of polymers as thin films (A), and CV curves of polymer films on a Pt electrode measured in $0.1 \mathrm{M} \mathrm{Bu}_{4} \mathrm{NPF}_{6}$ acetonitrile solutions for oxidation at a scan rate of $100 \mathrm{mV} / \mathrm{s}$ (B).

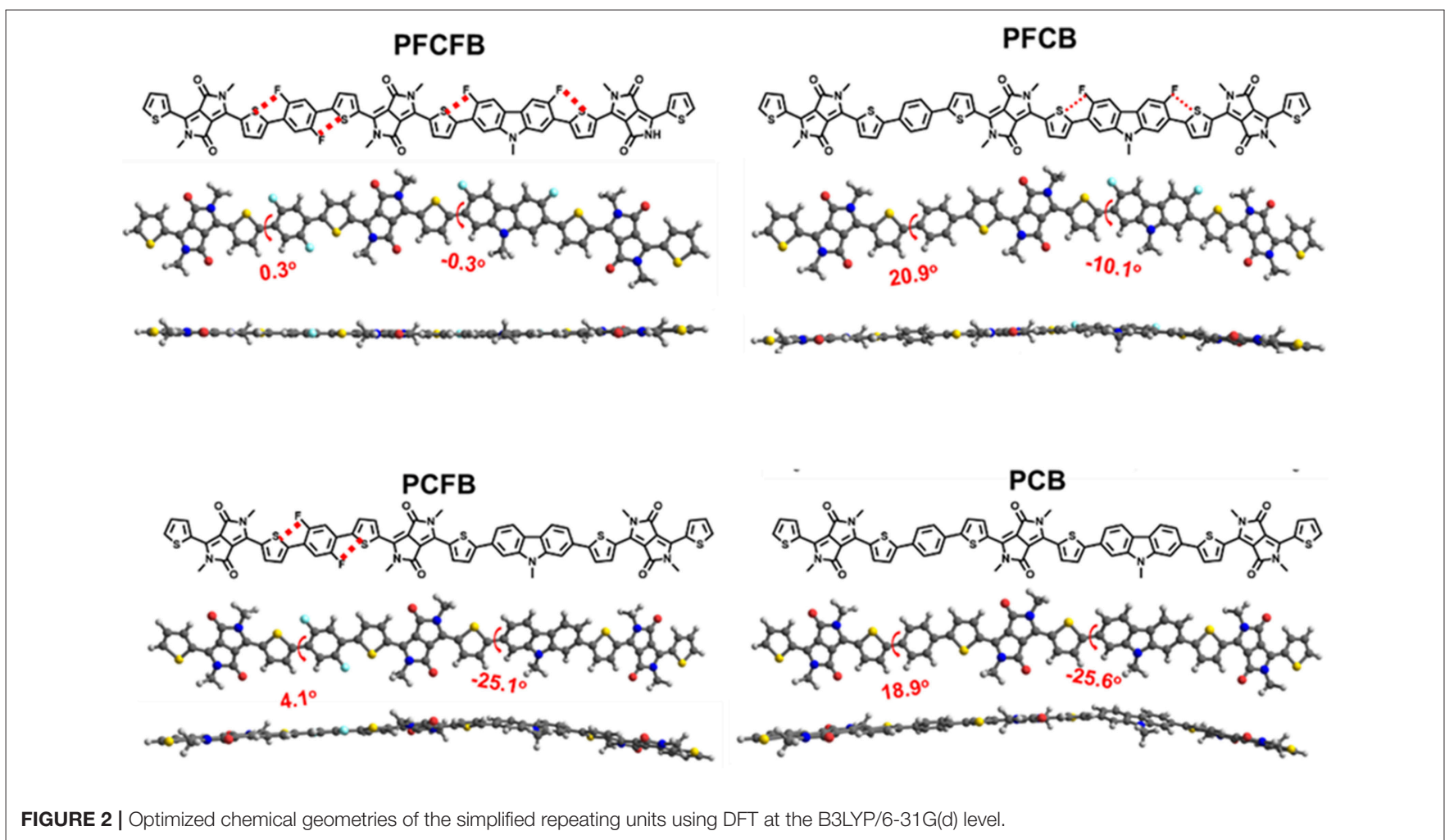

PCB, respectively. The consequence indicates that PCFB with fluorinated benzene but non-fluorinated carbazole moieties in the polymer chain possesses the minimum lamellar distance, while PFCFB with both fluorinated benzene and fluorinated carbazole moieties shows the minimum $\pi-\pi$ stacking distance. Since the long-wavelength absorption peak $(700 \sim 750 \mathrm{~nm})$ is susceptible to the aggregation of polymer chains and the short-wavelength one (around $400 \mathrm{~nm}$ ) is influenced by the $\pi-\pi$ stacking of aromatic units, the XRD results are thus in line with the UV-vis absorption spectra of the polymers, where PCFB shows the most bathochromic-shifted peak in the long-wavelength region but PFCFB does so in the shortwavelength one.

\section{DENSITY FUNCTIONAL THEORY CALCULATIONS}

Density functional theory (DFT) calculations at the B3LYP/6$31 \mathrm{G}(\mathrm{d})$ level was used to investigate the chemical geometry and electronic structures of the simplified repeating units. As shown in Figure 2, the two important dihedral angles in the repeating units are marked. The one formed by benzene and thiophene is significantly reduced from about $20^{\circ}$ to only several degrees after fluorine substitution. However, the other one formed by carbazole and thiophene is quite large about $25^{\circ}$ and only decreased to $10^{\circ}$ after fluorine substitution. It is worth noting that these dihedral angles were approaching to zero degree after 

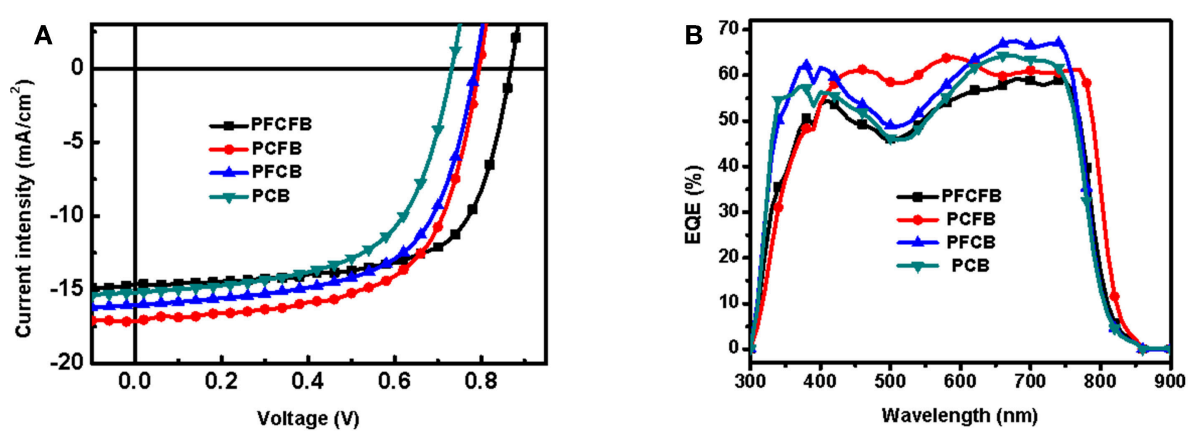

FIGURE 3 | J-V (A) and EQE (B) curves of OSCs based on PFCFB, PCFB, PFCB, and PCB.

TABLE 2 | Photovoltaic parameters of devices based on PFCFC, PCFB, PFCB, and $\mathrm{PCB}$.

\begin{tabular}{lccccc}
\hline Polymer & DIO & $\boldsymbol{V}_{\boldsymbol{o c}}(\mathbf{V})$ & $\boldsymbol{J}_{\boldsymbol{s c}}\left(\mathbf{m A} / \mathbf{c m}^{\mathbf{2}}\right)$ & FF & PCE (\%) \\
\hline PFCFB & $1 \%$ & 0.86 & $14.60(14.34)^{\mathrm{a}}$ & 0.66 & 8.48 \\
PCFB & $0.8 \%$ & 0.79 & $17.20(16.56)^{\mathrm{a}}$ & 0.62 & 8.46 \\
PFCB & $1 \%$ & 0.78 & $16.21(15.71)^{\mathrm{a}}$ & 0.61 & 7.73 \\
PCB & $1 \%$ & 0.73 & $15.19(14.91)^{\mathrm{a}}$ & 0.59 & 6.64 \\
\hline
\end{tabular}

${ }^{a}$ Calculated by EQE measurements.

fluorination of both the carbazole and the benzene units, which endows excellent planarity of the repeating unit based on PFCFB. This planarity guarantees the outstanding transport mobility of the polymers which may give the high FF of the devices. PCFB is the other one who possesses a moderate planarity with two dihedral angles of $4.1^{\circ}$ and $25.1^{\circ}$, which may give a reason why it has both a short lamellar and $\pi-\pi$ stacking distance. Such an enhanced planarity of the aromatic fragments in fluorinated polymer chains arises from the intramolecular F. . S interaction, which lock their planar conformations in the solid states (Jackson et al., 2013; Cheng et al., 2016). It is worth noting that the result of the calculations is consistent with the $\mathrm{X}$-ray diffractions. As shown in Table S2, polymer film based on PFCFB exhibit the lowest d-spacing distance about $3.70 \AA$, the one based on PCB own a d-spacing distance of $3.76 \AA$, and the d-spacing distance of the PFCB and PCFB was between PFCFB and PCB. This phenomenon arises from the different planarity of the polymers caused by the differences in intramolecular non-covalent interactions. The electronic properties are also investigated via DFT calculations (see Figure S3). The tendency was consistent with CV measurements. The HOMO energy level moved downwards after the introduction of $\mathrm{F}$ atoms, which will be helpful to enhance $V_{\text {oc }}$ of the devices based on fluorinated polymers.

\section{PHOTOVOLTAIC PROPERTIES}

The photovoltaic properties of the polymers was investigated using conventional device with a structure of ITO/PEDOT:PSS/polymer: $\mathrm{PC}_{71} \mathrm{BM} / \mathrm{LiF} / \mathrm{Al}$ in which ITO and PEDOT:PSS mean indium tin oxide, $\operatorname{poly}(3,4-$ ethylenedioxythiophene):poly(styrenesulfonate), phenyl- $\mathrm{C}_{71}$ butyric acid methyl, respectively. Various conditions were employed to optimize the photovoltaic performance, such as different ratios of donor/acceptor, solvent additives and spin-coating rates. The optimized current-voltage $(J-V)$ curves is shown in Figure 3. The active layer was spin-coated on the substrate with a solution of $\mathrm{CHCl}_{3}$ (with DIO as the additive). The optimized donor to acceptor weight ratio is 1:2 (w/w), and the optimized thickness is $100 \mathrm{~nm}$ by a spin-coating rate about $1,100 \mathrm{r} / \mathrm{min}$ with dilute polymer concentration of $3 \mathrm{mg} / \mathrm{mL}$. The optimized photovoltaic parameters were summarized in Table 2. Devices based on PFCFB and PCFB gave the high PCE of 8.48 and $8.46 \%$, respectively. It should be noted that PFCFB shows a different photovoltaic performance with PCDPP (Liu et al., 2016), which has a similar molecular structure as PFCFB. The difference comes from two aspects. First, PFCFB has a straight alkyl chain (n-octyl) on the carbazole unit; however, PCDPP has a branched one (2-ethylhexyl). Second, the processing solvents for depositing the active layer are different. The active layer was deposited from chlorobenzene solutions for PCDPP based device (Liu et al., 2016). In contrast, the active layer was deposited from a solution of $\mathrm{CHCl}_{3}$ for PFCFB. Here, the reason for using a solution of $\mathrm{CHCl}_{3}$ is that $\mathrm{PCFB}$ dissolves better in $\mathrm{CHCl}_{3}$ than in chlorobenzene. In order to make a comparison with the other three compounds, we thus chose chloroform as the processing solvent. The optimized PFCB and PCB based devices gave a relatively low PCE of 7.73 and $6.64 \%$, respectively. Moreover, the $V_{\text {oc }}$ of these devices was decreased with the reduction of $\mathrm{F}$ atoms due to the increase of HOMO energy level of polymers. Typically, the $V_{\text {oc }}$ of PFCFB based device was $0.86 \mathrm{~V}$ which is among the highest $V_{\text {oc }}$ of DPP-based polymers (Liu et al., 2016). The $V_{\text {oc }}$ of PCB based device was decreased about $15 \%$ with a value of $0.73 \mathrm{~V}$. The elevated $J_{\mathrm{sc}}$ of PFCB and PCFB based devices relative to that of $\mathbf{P C B}$ based one can be attributed to the reduced $\pi-\pi$ stacking distance which facilitates the charge transport (vide infra). Although PFCFB demonstrated the highest $V_{\text {oc }}$ among the four polymers, it shows the lowest $J_{\mathrm{sc}}$ value which arises from its low photoresponse in the wavelength range of 600-800 nm. External quantum efficiency (EQE) measurements were performed under monochromatic irradiation to investigate the spectral photoresponse and to verify the $J_{\mathrm{sc}}$ obtained from $J-V$ curves. The photo-electron response region was contributed by both the two components of the blend film. In addition, the edge of EQE curves were mainly decided by the UV-vis absorption of the polymers due to the narrow absorption of the 

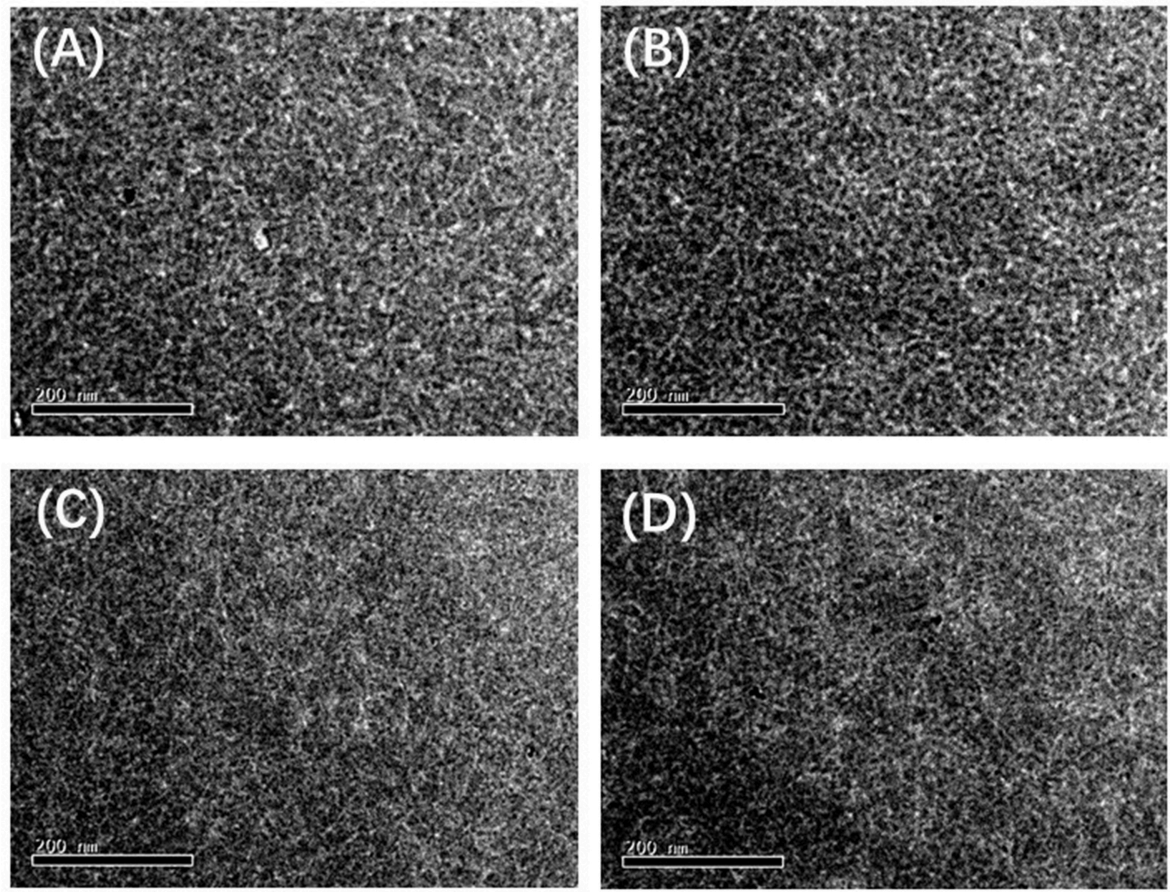

FIGURE 4 | TEM images of the blend films based on the polymer (A) PFCFB, (B) PCFB, (C) PFCB, and (D) PCB.

$\mathrm{PC}_{71} \mathrm{BM}$. Therefore, devices based on PCFB exhibit the broadest photo-electron response region, while PCB based devices possess the narrowest one. It is worth noting that the $J_{\mathrm{sc}}$ obtained from EQE curves is within $5 \%$ deviation to that of $J$ - $V$ curves.

\section{CHARGE TRANSPORT PROPERTIES}

The charge transport properties were characterized to further expose the differences in the four polymers. Hole and electron mobilities were measured by the space-charge-limited-current (SCLC) method with a structure of ITO/PEDOT:PSS/active layer/Au and ITO/ZnO/active layer/Al, respectively (shown in Figure S4). The hole and electron mobilities were listed in Table S3. The hole and electron mobility of PCFB was the highest one with a value of $4.63 \times 10^{-4}$ and $2.40 \times 10^{-4} \mathrm{~cm}^{2} \mathrm{~V}^{-1} \mathrm{~s}^{-1}$, respectively, which leads to the high $J_{\mathrm{sc}}$ of optimized device based on PCFB.

\section{FILM MORPHOLOGIES}

In order to better understand the fluorine effect on the photovoltaic performance, the morphologies of the blend films were investigated by atomic force microscope (AFM) and transmission electron microscope (TEM). As shown in Figure S5, the corresponding root-mean-square (RMS) roughness $\left(R_{\mathrm{q}}\right)$ values of PFCFB, PCFB, PFCB, and PCB based films are $1.51,1.77,1.41$, and $1.26 \mathrm{~nm}$, respectively. Networks of polymer fibrils can be found in the blended films (see Figure 4), which facilitate the charge separation and transport. Specially, proper aggregation was observed in Figure S5B based on PCFB which may explain why its hole and electron mobility is the highest and give the highest $J_{\mathrm{sc}}$.

\section{CONCLUSION}

In summary, regioregular terpolymers by changing $\mathrm{F}$ atoms in the various moieties in the polymer chain were carefully designed and synthesized by Suzuki coupling. These polymers showed broad absorption in the visible region and exhibited a low bandgap $<1.6 \mathrm{eV}$. From DFT calculations we know that the introduction of $\mathrm{F}$ atoms can flatten the molecular geometry between adjacent aromatic units due to the intramolecular supramolecular interaction. By introduction of $\mathrm{F}$ atoms to the benzene or carbazole segments or both of them, the molecular geometry can be modulated. Among the four terpolymers, PFCFB exhibited an excellent planarity with low dihedral angles. PCFB and PFCB showed a less good planarity than PFCFB but they are still much better than the unfluorinated one (PCB). Their molecular geometries thus influence the corresponding UV-vis spectra and charge transport properties. The introduction of $\mathrm{F}$ atom into the polymer chains can also significantly affect their energy levels. We demonstrate that PFCFB based devices have the highest $V_{\text {oc }}$ of $0.86 \mathrm{~V}$ which seriously reduce to $0.73 \mathrm{~V}$ after the remove of $\mathrm{F}$ atoms (the PCB case), while PCFB based ones give the highest $J_{\mathrm{sc}}$ of $17.20 \mathrm{~mA} / \mathrm{cm}^{2}$. For these two polymers (PFCFB and PCFB), the highest PCE of $\sim 8.5 \%$ was achieved. Our results give a clear explanation that how $\mathrm{F}$ atoms take effect on the regioregular terpolymers and modulate their photovoltaic performances. We show that selecting proper donor units with $\mathrm{F}$ atom to fabricate 
copolymers is an effective way to realizing high-efficiency polymer solar cells based on DPP units by enhancing in both $V_{\text {oc }}$ and $J_{\text {sc }}$.

\section{DATA AVAILABILITY}

The raw data supporting the conclusions of this manuscript will be made available by the authors, without undue reservation, to any qualified researcher.

\section{AUTHOR CONTRIBUTIONS}

All authors listed have made a substantial, direct and intellectual contribution to the work, and approved it for publication.

\section{REFERENCES}

Albrecht, S., Janietz, S., Schindler, W., Frisch, J., Kurpiers, J., Kniepert, J., et al. (2012). Fluorinated copolymer PCPDTBT with enhanced opencircuit voltage and reduced recombination for highly efficient polymer solar cells. J. Am. Chem. Soc. 134, 14932-14944. doi: 10.1021/ja3 05039j

Ashraf, R. S., Meager, I., Nikolka, M., Kirkus, M., Planells, M., Schroeder, B. C., et al. (2015). Chalcogenophene comonomer comparison in small band gap diketopyrrolopyrrole-based conjugated polymers for high-performing fieldeffect transistors and organic solar cells. J. Am. Chem. Soc. 137, 1314-1321. doi: $10.1021 /$ ja5 $511984 \mathrm{q}$

Cheng, Y., Qi, Y., Tang, Y., Zheng, C., Wan, Y., Huang, W., et al. (2016). Controlling intramolecular conformation through nonbonding interaction for soft-conjugated materials: molecular design and optoelectronic properties. J. Phys. Chem. Lett. 7, 3609-3615. doi: 10.1021/acs.jpclett.6b01695

Choi, H., Ko, S.-J., Kim, T., Morin, P.-O., Walker, B., Lee, B. H., et al. (2015). Smallbandgap polymer solar cells with unprecedented short-circuit current density and high fill factor. Adv. Mater. 27, 3318-3324. doi: 10.1002/adma.201501132

Dou, L., Chang, W. H., Gao, J., Chen, C. C., You, J., and Yang, Y. (2013). A selenium-substituted low-bandgap polymer with versatile photovoltaic applications. Adv. Mater. 25, 825-831. doi: 10.1002/adma.201203827

Dou, L., You, J., Yang, J., Chen, C.-C., He, Y., Murase, S., et al. (2012). Tandem polymer solar cells featuring a spectrally matched low-bandgap polymer. Nat. Photon. 6, 180-185. doi: 10.1038/nphoton.2011.356

Du, C., Li, W., Duan, Y., Li, C., Dong, H., Zhu, J., et al. (2013). Conjugated polymers with 2,7-linked 3,6-difluorocarbazole as donor unit for high efficiency polymer solar cells. Polym. Chem. 4:2773. doi: 10.1039/c3py00177f

Duan, C., Gao, K., van Franeker, J. J., Liu, F., Wienk, M. M., and Janssen, R. A. (2016). Toward practical useful polymers for highly efficient solar cells via a random copolymer approach. J. Am. Chem. Soc. 138, 10782-10785. doi: $10.1021 /$ jacs.6b06418

Fei, Z., Boufflet, P., Wood, S., Wade, J., Moriarty, J., Gann, E., et al. (2015). Influence of backbone fluorination in regioregular poly(3alkyl-4-fluoro)thiophenes. J. Am. Chem. Soc. 137, 6866-6879. doi: 10.1021 /jacs.5b02785

Hendriks, K. H., Heintges, G. H. L., Gevaerts, V. S., Wienk, M. M., and Janssen, R. A. J. (2013). High-molecular-weight regular alternating diketopyrrolopyrrolebased terpolymers for efficient organic solar cells. Angew. Chem. Int. Ed. 52, 8341-8344. doi: 10.1002/anie.201302319

Hendriks, K. H., Li, W., Heintges, G. H., van Pruissen, G. W., Wienk, M. M., and Janssen, R. A (2014a). Homocoupling defects in diketopyrrolopyrrole-based copolymers and their effect on photovoltaic performance. J. Am. Chem. Soc. 136, 11128-11133. doi: 10.1021/ja505574a

Hendriks, K. H., Li, W., Wienk, M. M., and Janssen, R.A. J. (2014b). Small-bandgap semiconducting polymers with high near-infrared photoresponse. J. Am. Chem. Soc. 136, 12130-12136. doi: 10.1021/ja506265h

\section{ACKNOWLEDGMENTS}

Financial support from the NSF of China (21574013, 51673028, 51003006, 21734009, 21421003), the Program for Changjiang Scholars and Innovative Research Team in University are gratefully acknowledged.

\section{SUPPLEMENTARY MATERIAL}

The Supplementary Material for this article can be found online at: https://www.frontiersin.org/articles/10.3389/fchem. 2019.00333/full\#supplementary-material

Experimental details, instruments, OPV fabrication and measurements. XRD, TGA, SCLC measurements, DFT calculations, and AFM images.

Huo, L., Xue, X., Liu, T., Xiong, W., Qi, F., Fan, B., et al. (2018). Subtle side-chain engineering of random terpolymers for high-performance organic solar cells. Chem. Mater. 30, 3294-3300. doi: 10.1021/acs.chemmater.8b00510

Jackson, N. E., Savoie, B. M., Kohlstedt, K. L., Olvera de la Cruz, M., Schatz, G. C., Chen, L. X., et al. (2013). Controlling conformations of conjugated polymers and small molecules: the role of nonbonding interactions. J. Am. Chem. Soc. 135, 10475-10483. doi: 10.1021/ja403667s

Jo, J. W., Jung, J. W., Jung, E. H., Ahn, H., Shin, T. J., and Jo, W. H. (2015). Fluorination on both $\mathrm{D}$ and $\mathrm{A}$ units in $\mathrm{D}-\mathrm{A}$ type conjugated copolymers based on difluorobithiophene and benzothiadiazole for highly efficient polymer solar cells. Energy Environ. Sci. 8, 2427-2434. doi: 10.1039/c5ee00855g

Kawashima, K., Fukuhara, T., Suda, Y., Suzuki, Y., Koganezawa, T., Yoshida, H., et al. (2016). Implication of fluorine atom on electronic properties, ordering structures, and photovoltaic performance in naphthobisthiadiazolebased semiconducting polymers. J. Am. Chem. Soc. 138, 10265-10275. doi: $10.1021 /$ jacs.6b05418

Kim, H., Lee, H., Seo, D., Jeong, Y., Cho, K., Lee, J., et al. (2015). Regioregular low bandgap polymer with controlled thieno[3,4-b]thiophene orientation for high-efficiency polymer solar cells. Chem. Mater. 27, 3102-3107. doi: 10.1021/acs.chemmater.5b00632

Lee, J. W., Ahn, H., and Jo, W. H. (2015). Conjugated random copolymers consisting of pyridine- and thiophene-capped diketopyrrolopyrrole as coelectron accepting units to enhance both JSC and VOC of polymer solar cells. Macromolecules 48, 7836-7842. doi: 10.1021/acs.macromol.5b01826

Lee, W., Lee, H. D., Bae, J. H., and Jung, J. W. (2016). Fluoro-substituted low band gap polymers based on isoindigo for air-stable polymer solar cells with high open circuit voltages. Org. Electron. 39, 85-90. doi: 10.1016/j.orgel.2016. 09.026

Li, C., Yu, C., Lai, W., Liang, S., Jiang, X., Feng, G., et al. (2018). Multifunctional diketopyrrolopyrrole-based conjugated polymers with perylene bisimide side chains. Macromol. Rapid. Commun. 39:e1700611. doi: 10.1002/marc.201700611

Li, C., Zhang, A., Wang, Z., Liu, F., Zhou, Y., Russell, T. P., et al. (2016). All polymer solar cells with diketopyrrolopyrrole-polymers as electron donor and a naphthalenediimide-polymer as electron acceptor. RSC Adv. 6, 35677-35683. doi: $10.1039 / \mathrm{c} 6 \mathrm{ra03681 \textrm {c }}$

Li, G., Gong, X., Zhang, J., Liu, Y., Feng, S., Li, C., et al. (2016). 4-Alkyl3,5-difluorophenyl-Substituted Benzodithiophene-Based Wide Band Gap Polymers for High-Efficiency Polymer Solar Cells. ACS Appl. Mater. Interfaces 8, 3686-3692. doi: 10.1021/acsami.5b08769

Li, W., Albrecht, S., Yang, L., Roland, S., Tumbleston, J. R., McAfee, T., et al. (2014a). Mobility-controlled performance of thick solar cells based on fluorinated copolymers. J. Am. Chem. Soc. 136, 15566-15576. doi: $10.1021 /$ ja5067724

Li, W., Hendriks, K. H., Furlan, A., Roelofs, W. S., Meskers, S. C., Wienk, M. M., et al. (2014b). Effect of the fibrillar microstructure on the efficiency of high molecular weight diketopyrrolopyrrole-based polymer solar cells. Adv. Mater. 26, 1565-1570. doi: 10.1002/adma.201304360 
Li, W., Hendriks, K. H., Wienk, M. M., and Janssen, R. A. J. (2015). Diketopyrrolopyrrole polymers for organic solar cells. Acc. Chem. Res. 49, 78-85. doi: 10.1021/acs.accounts.5b00334

Li, Z., Jiang, K., Yang, G., Lai, J. Y., Ma, T., Zhao, J., et al. (2016). Donor polymer design enables efficient non-fullerene organic solar cells. Nat. Commun. 7:13094. doi: 10.1038/ncomms13094

Liu, Y., Li, G., Zhang, Z., Wu, L., Chen, J., Xu, X., et al. (2016). An effective way to reduce energy loss and enhance open-circuit voltage in polymer solar cells based on a diketopyrrolopyrrole polymer containing three regular alternating units. J. Mater. Chem. A 4, 13265-13270. doi: 10.1039/c6ta05471d

Liu, Y., Zhang, C. E., Hao, D., Zhang, Z., Wu, L., Li, M., et al. (2018). Enhancing the performance of organic solar cells by hierarchically supramolecular selfassembly of fused-ring electron acceptors. Chem. Mater. 30, 4307-4312. doi: 10.1021/acs.chemmater.8b01319

Nielsen, C. B., Turbiez, M., and McCulloch, I. (2013). Recent advances in the development of semiconducting DPP-containing polymers for transistor applications. Adv. Mater. 25, 1859-1880. doi: 10.1002/adma.201201795

Park, J. H., Jung, E. H., Jung, J. W., and Jo, W. H. (2013). A fluorinated phenylene unit as a building block for high-performance $\mathrm{n}$-type semiconducting polymer. Adv. Mater. 25, 2583-2588. doi: 10.1002/adma.201205320

Qin, T., Zajaczkowski, W., Pisula, W., Baumgarten, M., Chen, M., Gao, M., et al. (2014). Tailored Donor-Acceptor Polymers with an A-D1-A-D2 Structure: controlling intermolecular interactions to enable enhanced polymer photovoltaic devices. J. Am. Chem. Soc. 136, 6049-6055. doi: 10.1021/ja500935d

Sonar, P., Singh, S. P., Li, Y., Soh, M. S., and Dodabalapur, A. (2010). A Lowbandgap diketopyrrolopyrrole-benzothiadiazole-based copolymer for highmobility ambipolar organic thin-film transistors. Adv. Mater. 22, 5409-5413. doi: 10.1002/adma.201002973

Tanaka, H., Shizu, K., Nakanotani, H., and Adachi, C. (2013). Twisted intramolecular charge transfer state for long-wavelength thermally activated delayed fluorescence. Chem. Mater. 25, 3766-3771. doi: 10.1021/cm402428a

Wang, B., Huynh, T. -P., Wu, W., Hayek, N., Do, T. T., Cancilla, J. C., et al. (2016). A highly sensitive diketopyrrolopyrrole-based ambipolar transistor for selective detection and discrimination of xylene isomers. Adv. Mater. 8, 4012-4018. doi: 10.1002/adma.201505641

Wang, X., Deng, W., Chen, Y., Wang, X., Ye, P., Wu, X., et al. (2017). Fine-tuning solid state packing and significantly improving photovoltaic performance of conjugated polymers through side chain engineering via random polymerization. J. Mater. Chem. A 5, 5585-5593. doi: 10.1039/c6ta10864d.
Wang, Y., Hasegawa, T., Matsumoto, H., Mori, T., and Michinobu, T. (2017). DA1-D-A2 Backbone strategy for benzobisthiadiazole based n-channel organic transistors: clarifying the selenium-substitution effect on the molecular packing and charge transport properties in electron-deficient polymers. Adv. Fun. Mater. 27:1701486. doi: 10.1002/adfm.201701486

You, J., Dou, L., Yoshimura, K., Kato, T., Ohya, K., Moriarty, T., et al. (2013). A polymer tandem solar cell with $10.6 \%$ power conversion efficiency. Nat. Commun. 4:1446. doi: 10.1038/ncomms2411

Yu, Y., Wu, Y., Zhang, A., Li, C., Tang, Z., Ma, W., et al. (2016). Diketopyrrolopyrrole polymers with thienyl and thiazolyl linkers for application in field-effect transistors and polymer solar cells. ACS Appl. Mater. Interfaces. 8, 30328-30335. doi: 10.1021/acsami. $6 \mathrm{~b} 06967$

Zhang, C. E., Feng, S., Liu, Y., Hou, R., Zhang, Z., Xu, X., et al. (2017). Effect of non-fullerene acceptors' side chains on the morphology and photovoltaic performance of organic solar cells. ACS Appl. Mater. Interfaces. 9, 33906-33912. doi: 10.1021/acsami.7b09915

Zhang, Q., Kelly, M. A., Bauer, N., and You, W. (2017). The curious case of fluorination of conjugated polymers for solar cells. Acc. Chem. Res. 50, 2401-2409. doi: 10.1021/acs.accounts.7b00326

Zhao, W., Li, S., Yao, H., Zhang, S., Zhang, Y., Yang, B., et al. (2017). Molecular optimization enables over $13 \%$ efficiency in organic solar cells. J. Am. Chem. Soc. 139, 7148-7151. doi: 10.1021/jacs.7b02677

Zheng, Z., Zhang, S., Zhang, J., Qin, Y., Li, W., Yu, R., et al. (2016). Over $11 \%$ Efficiency in tandem polymer solar cells featured by a lowband-gap polymer with fine-tuned properties. Adv. Mater. 8, 5133-5138. doi: 10.1002/adma.201600373

Conflict of Interest Statement: The authors declare that the research was conducted in the absence of any commercial or financial relationships that could be construed as a potential conflict of interest.

Copyright (C) 2019 Zhang, Liu, Tu, Ming, Xu and Bo. This is an open-access article distributed under the terms of the Creative Commons Attribution License (CC BY). The use, distribution or reproduction in other forums is permitted, provided the original author(s) and the copyright owner(s) are credited and that the original publication in this journal is cited, in accordance with accepted academic practice. No use, distribution or reproduction is permitted which does not comply with these terms. 